\title{
Cerebrospinal fluid
}

\section{E J Thompson}

\section{Normal physiology of blood-brain barriers}

Despite the existence of several "barriers" between the blood and the brain, CSF can still be considered as an ultrafiltrate of plasma. There are, nevertheless, exceptions to this generality. Perhaps the most obvious relates to CSF cells, of which about two thirds are found to be lymphocytes and one third monocytes, whereas the blood contains mainly granulocytes. Most immunologists could thus be forgiven for assuming that CSF is a type of lymphatic fluid. More recent trends in immunology ${ }^{1}$ have spoken of "regional" immunology in which localised variations in immune modulators cause the nature of the response to vary from region to region-that is, the overall lymphatic/cytokine milieu is different in the brain from that in, say, the gut or the lung. Due to the higher brain concentration of TGF- $\beta$ the CNS tends to emphasise the cell mediated (Th2) over the humoral (Th1) response, at least in experimental autoimmune encephalomyelitis. ${ }^{2}$

In normal CSF, about $80 \%$ of proteins are transudated from plasma and $20 \%$ are synthesised by the brain. Under pathological conditions there are striking alterations. The bulk of the normal CSF proteins are derived from the plasma. There are rules which govern the process of ultrafiltration but, as the word "ultrafiltrate" suggests, the molecular size is of primary importance. The word "barrier" suggests some sort of impervious limit which cannot ever be breached. All known proteins pass from plasma into CSF, however, and mainly do so in inverse relation to their molecular size. ${ }^{3}$ It is important to realise that none is excluded by any "barrier". The barrier is only relative and probably best understood as a function based on hydrated molecular size. There are other functions, notably lipophilicity, which mainly apply to substances with molecular weights less than $500 \mathrm{Da}$. Molecular charge plays a lesser part in determining ease of entry into the CSF from the plasma. Acidic proteins have a slight advantage over proteins with a more basic charge. Because of the difference in composition of CSF compared with a parallel blood (plasma or serum) sample, comparisons between the two fluids are always necessary to detect local synthesis of any given analyte, antigen, or antibody. This demonstration of local synthesis is based on the initial statement that CSF is mainly an ultrafiltrate of plasma.
Figure 1 shows the six main barriers and sources of CSF production.

1 The blood-CSF barrier-The choroid plexus is the main source of CSF, accounting for two thirds of the volume. Production of CSF is rarely affected by abnormalities of the choroid plexus;

2 the blood-brain barrier-The rest of the brain vasculature accounts for one third of the CSF volume. Many abnormalities affect this route, the most common being brain tumours. Lesions which produce Froin's syndrome give the highest CSF protein concentrations;

3 the blood-dorsal root barrier - this represents the vasculature within the dorsal root ganglia, which is more permeable than the rest of the brain vasculature. In the Guillain-Barré syn-

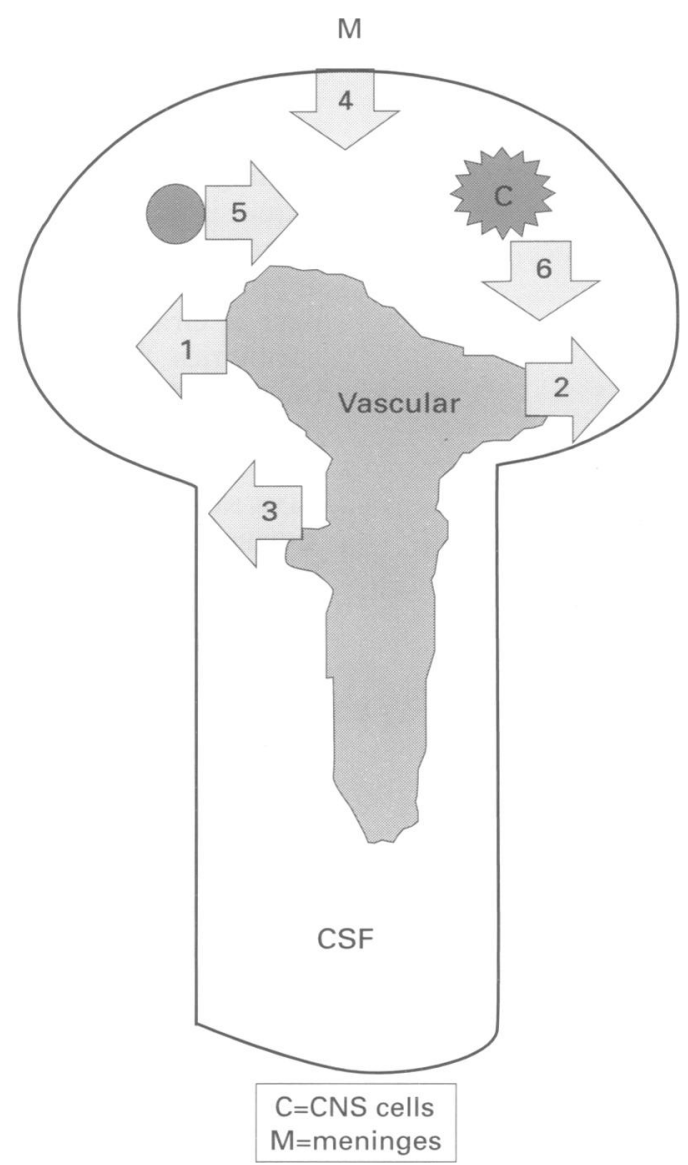

Figure 1 CSF barriers and sources: $1=$ blood-CSF barrier; 2 = blood-brain barrier; $3=$ blood-dorsal root barrier; $4=$ meninges; $5=$ wandering cells; $6=$ sessile cells (for details see text). 
drome there can be dramatic increases in the total protein concentration surrounding the spinal cord, whereas the total protein in the ventricles is low;

4 the meninges-The meninges do not normally produce any CSF. In meningitis there is a dramatic increase in the permeability to cells and serum proteins;

5 CSF cells-Normal CSF contains a cell ratio of two thirds lymphocytes and one third monocytes. In various inflammatory diseases, plasma cells are lymphocytes actively secreting antibody whereas polymorphs typically imply bacterial infection;

6 the structural cells which constitute the nervous system-Four marker proteins correspond to the four cell types: neurons-enolase; astrocytes-glial fibrillary acidic protein; oligodendrocytes-myelin basic protein; microgliaferritin.

Cells enter the CSF using rules other than molecular size. Ignoring red cells, the blood mainly contains granulocytes (polymorphs) but these are essentially absent from normal CSF. Lymphocytes are the commonest cells in the CSF and are derived from the blood. Monocytes (macrophages) can either be derived from the blood or from the local microglia (which comprise about one third of brain cells), being a kind of sessile macrophage, which can thus present antigens to local lymphocytes.

\section{Methods of analysis of CSF and serum GRAM STAIN AND CULTURE USING TRADITIONAL GROWTH MEDIA}

The growth of bacteria from CSF in acute meningitis using standard molecular techniques is required to define the specific type of bacteria and to test for sensitivities to the appropriate antibiotics. It is essential to prepare a Gram stain to help select the initial antibiotics on the simple basis of whether there are Gram positive cocci or Gram negative rods.

\section{IMMUNODETECTION OF ANTIGEN AND ANTIBODY}

Immunoassays have evolved to detect the various antigens which may be found in the CSF. Initial work was done with counter immunoelectrophoresis which then evolved through latex agglutination, in which the surface of the latex beads was coated with antibody against the antigen in question, and finally the methodology evolved to use enzyme linked immunosorbent assay (ELISA) technology. This is basically a colorimetric technique in small microtitre wells.

In the detection of specific antibodies, the newest move in technology is to examine the oligoclonal antibody response with nitrocellulose immunoblotting, in which the nitrocellulose membrane has been previously impregnated with the relevant antigen. This provides additional information as to the underlying clonal pattern of the antibodies which can be different in the CSF from parallel serum, as will be shown below with the five types of pattern (using total IgG rather than antigen-specific $\operatorname{IgG}$ ).

\section{CYTOLOGY: CYTOSPIN; IMMUNOSTAINING}

The traditional procedure for cell counting is based on the number of cells per $\mu \mathrm{l}$. The use of the cytospin centrifuge allows $300 \mu \mathrm{l}$ to be effectively concentrated on to a single slide with the dimension of the cell pellet being only a few millimetres, ${ }^{4}$ which can be readily scanned under the microscope. Additional slides can also be prepared for immunostaining with a number of antigen specific reagents. ${ }^{5}$

Malignant cells are occasionally found in the CSF in cases of primary or secondary CNS tumours. The presence of plasma cells follows the general pattern previously noted that qualitative analysis can be more informative than quantitative analysis - that is, despite unequivocally normal CSF cell counts, there can be atypical, reactive lymphocytes or frank plasma cells. These typically coincide with the presence of oligoclonal IgG indicating local synthesis. ${ }^{6}$

\section{BIOCHEMISTRY: LACTATE}

Lactate gives more information than the traditional estimation of glucose in distinguishing bacterial (higher lactate) from viral meningitis. The fluoride (or oxalate) bottle, which has usually been dedicated to glucose, can be used to preserve the lactate specimen. In the blood, however, the specimen should be collected into perchloric acid to stop any further metabolism of the lactate present.

\section{ISOELECTRIC FOCUSING}

By international consensus five types of banding pattern are recognised when comparing the isoelectric focusing of CSF and parallel serum from the same patient (see fig 2 ).

\section{POLYMERASE CHAIN REACTION (PCR)}

This technique is now popular for the diagnosis of herpes simplex encephalitis and has largely replaced the use of brain biopsy. Many investigators have found that this is a reliable test for herpes encephalitis, but a slight degree of caution should still be exercised. Although false positives in the PCR technique are notorious, false negative results have also been noted, especially depending on the time of sampling of CSF. Whereas the viral DNA can often be detected in the first seven to 10 days (when the antibody is negative), following this the obverse applies: there will be positive antibody with negative PCR.? Therefore CSF should be screened for antibodies against herpes simplex, as well as looking for the herpes DNA. ${ }^{8}$ It seems likely that this will be true of other viruses as well. Many other DNA sequences have been looked for using PCR, and also RNA viruses, when reverse transcriptase is used first to convert the RNA into DNA. Recent papers sound a note of caution for some of these techniques. ${ }^{9}$ One attempt at quality control produced very sobering results when several different laboratories achieved a wide range of false positives and false 
Figure 2: The five types of CSF/serum banding patterns: Type 1 is normal with a polyclonal response in both CSF and serum; type 2 is a typical CSF oligoclonal response with the parallel serum showing a normal polyclonal response; type 3 is the "systemic + superimposed local synthesis" picture in which there are oligoclonal patterns in both CSF and serum but they differ in the isoelectric points ( $p I)$ of the bands and/or their relative peak height ratios between the bands in the two fluids. It is also called the "greater than" pattern since there are a greater number of oligoclonal bands in CSF than in serum; type 4 has been termed the "mirror" pattern in which the oligoclonal pattern in CSF and serum is essentially the same. This reflects primarily a systemic disease or, if there is infection in the brain, such as meningitis, the systemic response plays the predominant part; type 5 is the monoclonal response which is typical for paraproteins and shows roughly three to five regularly spaced bands of which the most prominent is near the cathode. Successively decreasing amounts of band staining are found towards the anode.

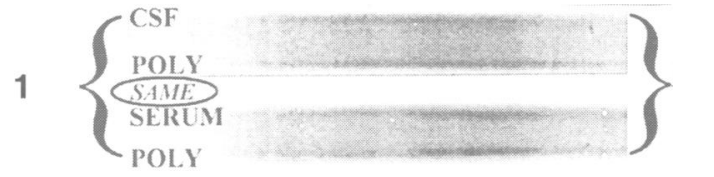

the ultraviolet through visible light to allow expression of the peak height ratios of different wavelengths. Raised total protein concentration usually produces absorption due to tyrosine at $280 \mathrm{~nm}$, whereas the other haemoglobin pigments have distinct wavelengths, which depend on the time the haemoglobin has been in the CSF, as it is further metabolised in vivo into derivative bile products. ${ }^{13}$

ELISA: FERRITIN (NECROSIS)

The ELISA technique is likely to replace many radioimmunoassays, and a good example of the technique is the measurement of ferritin. Ferritin concentration in CSF is a particularly good test for intracranial bleeding (causing CNS necrosis) and is more sensitive than the traditional technique of testing for xanthochromia. ${ }^{14}$ Because ferritin is normally produced locally by the microglial cells, any increase in activity of these cells due either to phagocytosis (secondary to necrosis) or in response to a strong immunological stimulus such as infection, will result in dramatic increases in ferritin in CSF.

\section{IMMUNOELECTROPHORESIS: $\beta 2$ TRANSFERRIN (CSF MARKER)}

The $\beta 2$ transferrin protein (originally called tau protein) is the best marker to detect spinal fluid in nasal secretions in suspected CSF rhinorrhoea. ${ }^{15}$ This is performed using an immunostain of nitrocellulose blotting with transferrin antibody. The $\beta 2$ transferrin protein represents transferrin without the sialic acid residues and is thus an unequivocal marker for an unknown fluid being derived from CSF rather than other analytes (for example, glucose) which are less reliable markers for CSF.

\section{MOLECULAR SIZING: SMALL (FREE LIGHT CHAINS); LARGE (POLYMERS)}

Free light chains have traditionally been estimated using preadsorbed antiserum which can unfortunately still show some cross reactivity with bound light chains. Polyacrylamide gel electrophoresis separates proteins on the basis of their molecular size. Free light chains are by definition not bound to heavy chains and run ahead of the traditional gamma region, where all the intact (bound) immunoglobulins migrate. Two replicate nitrocellulose blots are applied to the polyacrylamide gel, one is immunostained with antikappa and the other with antilambda, to look for a discrepancy in the two light chain patterns, which is then consistent with local synthesis of IgG in the CNS. It also indicates recent antigenic stimulation in the CNS as may be seen in multiple sclerosis relapses.

Haptoglobin polymers (of large molecular size) are the most subtle test for barrier damage. The concentrations are also increased in relation to relapse in multiple sclerosis. ${ }^{16}$ The concentrations of haptoglobin polymers increase with normal aging.

CSF FLOW RATES: BRAIN PROTEINS

Cerebrospinal fluid is produced at the rate of
The analysis of haemoglobin pigments in the CSF requires scanning a broad spectrum from 


\begin{tabular}{l} 
Table 1 Antigen-specific \\
IgG studies on CSF \\
\hline Organism \\
\hline Bacteria: \\
S pneumoniae \\
H influenzae \\
N meningitidis \\
M tuberculosis \\
T pallidum \\
B burgdorferi \\
Viruses: \\
Measles \\
Herpes simplex types I, II \\
Varicella zoster \\
Rubella \\
Mumps \\
Cytomegalovirus \\
JC papova virus \\
ECHO virus \\
Epstein-Barr virus \\
Protozoans: \\
Toxoplasma \\
Malaria \\
Other \\
Kveim \\
Aspergillus \\
\hline
\end{tabular}

some $500 \mathrm{ml}$ per 24 hours, so that the fluid passing over the brain surface is renewed about once every six hours. A single lumbar puncture performed on a patient who has sustained cerebral injury will therefore only reflect the concentration of brain proteins which are found in the CSF at that particular point in time. Additional punctures show whether the concentration of brain specific proteins is increasing or decreasing, and over what interval of time. This kind of "vectorial" analysis gives the most useful information when applied to CSF (and serum) and is clearly set out in the example from Hans et $\mathrm{al}^{17}$ using the brain form (BB) of creatine kinase. They found that there is an exponential decay of enzyme activity during the first day after injury, with a half life of $4 \cdot 5$ hours.

\section{SERUM ACUTE PHASE MONITORING: C} REACTIVE PROTEIN

The concentrations of CSF $C$ reactive protein (CRP) are highly variable and have less value in clinical practice than the serum concentrations. ${ }^{18}$ In response to tissue injury of whatever aetiology, feedback via the cytokine network induces increases in several acute phase proteins, with the most dramatic increases being in the concentrations of CRP. Because of multiple possible causes, CRP cannot be used as a diagnostic test. Monitoring CRP, however, is helpful in a known disease such as systemic lupus to check for possible intercurrent infection and consequent modulation of the immunosuppressive therapy. It also provides a useful indication of immunological changes in multiple sclerosis as described by Dowling and Cook $^{19}$ and confirmed by us.

\section{URINARY SUBSTANCES: NEOPTERIN; MYELIN BASIC PROTEIN}

Neopterin, a byproduct of interferon- $\gamma$ induced macrophage activity, has previously been measured in the CSF and found to be related to recent exacerbations in multiple sclerosis. ${ }^{20}$ Increases in neopterin have been found during longitudinal studies of the urine in patients with the progressive form of multiple sclerosis as well as in the traditional relapsing and remitting type. ${ }^{21}$ Fragments of myelin basic protein have also been studied in relation to predicting response to therapy as shown below.

\section{Abnormal findings and their clinical relevance \\ SENSITIVITY AND SPECIFICITY FOR A GIVEN DISEASE}

The correct interpretation of any abnormal result cannot be understood without reference to the incidence of that abnormality in the relevant population, and the prior probability of, say, multiple sclerosis in different geographical areas. The predictive value (PV) for a positive (or a negative) result is largely dependent on this value for the prior probability and this is also reflected in the sensitivity of the test in question-that is, what percentage of patients with a certain disease will show the associated abnormality. ${ }^{22}$ As far as the use of various laboratory tests is concerned, the combination of sensitivity and specificity can also be expressed graphically by the receiver and operator curve. ${ }^{23}$

The question of specificity relates essentially to pathological controls-patients with diseases other than that in question-what percentage will show the specified abnormality? The finding of oligoclonal bands in the CSF but not the serum will reflect intrathecal inflammation, which is more common in chronic than acute diseases, as it takes about seven to 10 days for the plasma cells to begin to secrete IgG molecules.

The combined sensitivity and specificity of CSF oligoclonal bands gives considerable weight to the diagnosis of multiple sclerosis, not only because of the high sensitivity (of the order of $97 \%$ using the recommended techniques $^{24}$ ), but also for the specificity of pathogenesis, which if the patient does not have multiple sclerosis, at least gives a strong indication for an inflammatory disease (this will be discussed in further detail below, table 1).

\section{QUALITATIVE $V$ QUANTITATIVE ANALYSIS}

For many years now IgG, as well as albumin or total protein, have each been determined in CSF and parallel serum with the final evaluation being expressed by various mathematical formulae. These formulations are derived from either presumed simple linear relations or more complex curvolinear relations of $\mathrm{IgG}$ to albumin which are then used to quantify amounts of IgG which are ostensibly synthesised within the CNS compartment. It is of some historical note that the first demonstration by Kabat of abnormal CSF immunoglobulins was based on the qualitative method of electrophoresis before he subsequently published his paper on the precipitation of IgG to quantify its amounts. The strongest current consensus arrived at by a pan-European committee is that qualitative analysis using isoelectric focusing followed by immunofixation for IgG is a more sensitive and specific test for the diagnosis of multiple sclerosis than the quantitative determination of IgG/albumin in CSF/serum using any of the mathematical formulations, including the various non-linear representations. ${ }^{24}$

\section{AFFINITY MATURATION OF ANTIBODY RESPONSE}

It has been known for many years that patients with multiple sclerosis have locally synthesised antibodies against measles and other neurotropic agents. ${ }^{25}{ }^{26}$ It is not seriously considered, however, that measles or other viral antigens have a primary role in the pathogenesis of multiple sclerosis, merely that these antibodies, which have affinity, represent a secondary phenomenon. This is by contrast with patients with bona fide viral infections who have antibodies of high affinity. ${ }^{27}$ It has also been shown that patients with a viral infection of, for example, measles will have high affinity antibody to the 
causative virus, but the same patients will also have low affinity antibody against other unrelated viral antigens. ${ }^{27}$ Sodium thiocyanate can be used to measure the strength of the antigen-antibody bonds as it dissociates the hydrogen bonds between antigen and antibody. The lower the concentration of thiocyanate required to perform dissociation, the lower the affinity of the antigen/antibody bonding and vice versa. ${ }^{28}$ It is our experience that the diagnosis of a viral infection of the nervous system can be improved in some cases by using the combination of thiocyanate with antigen immunoblotting (qualitative) rather than the more traditional ELISA technique (quantitative). It is easy to visualise the qualitative difference between polyclonal, oligoclonal, and monoclonal IgG responses on nitrocellulose blots, whereas given the same IgG clones in solution, there is no discrimination using the ELISA technique between these three different types of antibody response. ${ }^{29}$ It is thus important for the determination of local IgG synthesis to compare the clonal pattern in CSF $v$ the corresponding serum, as well as any difference in affinity for the two parallel fluids being analysed. As in other branches of medicine, the diagnosis is often made by pattern recognition, in this case the pattern of the IgG clones. Thus any analysis of CSF should utilise tests for antigen as well as antibody against the specified antigen, as they will often produce complementary results rather than simply suggesting that one test is "better" than the other.

\section{Diseases}

INFECTION: ACUTE; CHRONIC; SECONDARY INFECTIONS (HIV)

A good indicator of bacterial meningitis is CSF lactate $>3.5 \mathrm{mmol} / \mathrm{l}$ in combination with a white count $>800$ cells $/ \mu$ l. $^{30}{ }^{31}$ Concentrations of serum lactate should always be measured in parallel specimens, to prove local synthesis of lactate within the CNS. Another indicator of infection is the serum concentration of CRP, which is much more reliable than the CSF concentration of CRP. There are some neurotropic brain pathogens which can be diagnosed using either the ELISA technique followed by affinity titration with thiocyanate, or the preferred additional technique of antigen specific immunoblotting again followed by thiocyanate titration. Table 1 gives a partial list of antibodies which have been detected for specific pathogens. ${ }^{32}$

INFLAMMATION: MULTIPLE SCLEROSIS; AUTOIMMUNE DISEASE

We shall consider in due course the differential diagnosis of a positive oligoclonal response within the CNS. The most common cause is multiple sclerosis; however, other infectious or autoimmune diseases must be excluded. The immunopathological interpretation of an oligoclonal response is that there must be a responsive antigen. In working through the differential diagnosis to try and find infectious antigens, or antibodies against other antigens such as double stranded DNA or cardiolipin antibody which are typical of autoimmune diseases, ${ }^{33}$ it is only after exclusion of the entire list of other possible causes of antigenic stimulation, that one can be left with a confident diagnosis of multiple sclerosis.

\section{NEOPLASIA}

Malignant cells can be found in the sediment of CSF and this can be reassuring as a direct demonstration of pathological cells in question. It is important to realise that there must be fluid communication between the tumour and the CSF for the cells to be shed into the CSF. The same is true for the determination of carcinoembryonic antigen (CEA). This is typically expressed as an index-that is, the concentration of CEA in CSF divided by the concentration in serum, which is further normalised by dividing the concentration of CSF albumin by the concentration of serum albumin. ${ }^{34}$ This is particularly useful in carcinoma involving the meninges and is generally of more value in secondary (metastatic) than primary CNS tumours. Patients with leukaemic infiltration of the CSF (including myeloma) can have the same index calculation performed in which the CSF concentration of paraprotein divided by its concentration in serum, is again normalised to the CSF albumin divided by the serum albumin. In other cases in which there is no tumour to be found within the CNS, nevertheless, there can be "remote" effects of carcinoma in which there is cross reactivity between various brain antigens and the tumour antigens in for example, lung or ovarian tumours. These patients can have an oligaclonal pattern or a "mirror" pattern. This is due to the strong systemic response which will be discussed further under the differential diagnosis of the "mirror" pattern.

\section{INJURY: CNS TRAUMA}

We have previously discussed the use of $\beta 2$ transferrin for the detection of CSF rhinorrhoea or otorrhoea. Various brain proteins have been used to diagnose and monitor patients with brain injury (for example, road traffic accidents) using several different brain proteins, mainly myelin basic protein or enolase, and to a lesser degree (although they show the same pattern), proteolipid protein, glial fibrillary acidic protein, ferritin, S-100, N-CAM protein, and myelin associated glycoprotein. ${ }^{35}$

As noted previously, the higher the concentrations or the more persistent the increases of these proteins, the worse is the likely outcome from the injury.

\section{HAEMORRHAGE: XANTHOCHROMIA AND} FERRTIIN

Although we have previously discussed the use of xanthochromia as an indicator of cerebral haemorrhage, CSF ferritin is a more sensitive marker. Nevertheless, the question of specificity for ferritin must also be considered in the context of possible brain infection. 
DESTRUCTION: CREUTZFELDT-JAKOB DISEASE In Creutzfeldt-Jakob disease the excessive proliferation of prion proteins produces large scale destruction of brain parenchyma due to the accumulation of the amyloid type of cross linked proteins. The extraordinarily high concentrations of normal brain proteins found in the CSF in Creutzfeldt-Jakob disease can also be helpful in its diagnosis, and are presumably related to the massive spongiform destruction of the CNS with the consequence that brain proteins are easily found in CSF and serum. ${ }^{36}$

BRAIN DEATH: ENOLASE

The concentrations of neuron specific enolase have been used by some investigators to confirm the clinical diagnosis of brain death. ${ }^{37}$

ISOLATED INRACRANIAL HYPERTENSION: IgG INDEX

Determination of CSF pressure using the manometer at the time of lumbar puncture is important not only for diagnosis but also for monitoring the treatment of isolated inracranial hypertension. An unexpected finding was the increase in the IgG index in isolated inracranial hypertension. ${ }^{22}$ The patients, however, had no oligoclonal bands in the CSF. Careful analysis of the serum concentrations of albumin and IgG (with reference to the CSF concentrations of albumin and $\mathrm{IgG}$ ) showed that imbalance for any of these variables can yield a consequent increase in the IgG index. The primary pathological process is therefore not thought to be related to an intrinsic intrathecal immunological abnormality but is probably related to secondary alterations in the body fluid balance within the compartments of CSF as contrasted with serum, which could thereby alter the relative amounts of CSF IgG when compared with the other three variables of the IgG index.

\section{Diagnosis by clinical and paraclinical techniques}

QUALITY ASSURANCE FOR RELIABLE DIAGNOSIS

The importance of quality assurance is to give independent objective evidence that the laboratory is sufficiently reliable to be able to support the diagnosis in question, using their chosen technology (which is hopefully up to date), and that their results are being interpreted correctly (as can be seen with the five types of band pattern in isoelectric focusing). Some tests have been subjected to the history of the swinging pendulum - there is an initial burst of enthusiasm, and as soon as people realise the test is not perfect, the pendulum swings back towards doubt. A more appropriate equilibrium is eventually reached. This can be seen not only for tests such as the PCR, but also for other paraclinical "tests" such as MRI. It is important to have blind specimens sent to the laboratory in question to ascertain the accuracy of diagnosis, and this also applies to qualitative judgements, not only for the five types of isoelectric focusing patterns but also for the exchange of slides between pathologists and radiographs between radiologists. ${ }^{38}$ Clinicians should still request that their colleagues in the pathology and radiology departments provide evidence that results from their techniques have been externally verified.

OLIGOCLONAL BANDS AND MRI ARE COMPLEMENTARY FOR DIAGNOSIS OF "EARLY" MULTIPLE SCLEROSIS

The relative risk ratio ( $R R)$, which is analogous to the predictive value (PV) for a positive result, was essentially the same for MRI and oligoclonal bands in the study of Miller et al. ${ }^{39}$ About half the patients who were positive for either MRI or CSF bands went on to develop multiple sclerosis. When both tests were positive, over $80 \%$ developed multiple sclerosis, but when both were negative, none developed multiple sclerosis. A subsequent study by Morrissey et $a l^{40}$ showed a dramatically lower response for CSF which could either be explained by the few specimens they examined or perhaps more relevant was the fact that the lumbar puncture was often performed early in the disease. By contrast, MRI can more easily be repeated at all stages of progression. Having personally reviewed many of the cases in question, it would seem that the paper of Miller et $a l^{39}$ is likely to provide the more representative result overall. This continues to be the fruitful subject of ongoing collaborative research. Independent studies of the quality assurance for the different IgG separation techniques ${ }^{41}$ have emphasised the idea that each different method for the demonstration of oligoclonal bands can yield dramatic differences, with electrophoresis on agarose with Coomassie staining being much less sensitive than isoelectric focusing followed by immunofixation for IgG. ${ }^{42}$ This also reinforces the point that any technique must be regularly assessed using external "blinded" specimens. This will ensure not only reproducibility but also the basic credibility of the laboratory results as well as the underlying methodology.

With the much vaunted recent success attributed to $\beta$ interferon trials, more patients are being recruited with "early" multiple sclerosis. It is thus particularly important that the diagnosis of "latent" or possible multiple sclerosis is made as confidently as possible. This means that MRI in itself may not be sufficient and, especially in these early cases, a lumbar puncture should provide the necessary extra degree of confidence to either accept or reject the diagnosis of multiple sclerosis. This has been the conclusion of most investigators in the field. ${ }^{394243}$

CSF and MRI are complementary for the diagnosis of "early" multiple sclerosis. When both are positive, there is a very high index of credibility for the disease. Conversely, when both are negative, the obverse is true.

DIFFERENTIAL DIAGNOSIS OF POSITIVE OLIGOCLONAL BANDS (LOCAL SYNTHESIS)

These disorders all have a common pathogenesis - namely, inflammatory disease - with the basic underlying question being what is the 
antigen? Having ruled out the common antigens, one is left by exclusion with the diagnosis of multiple sclerosis, for which there is as yet no known specific antigen. Table 2 gives an illustrative differential diagnosis.

Patients with SSPE will have high affinity antibodies to measles, whereas patients with multiple sclerosis will have low affinity antibodies directed against measles. ${ }^{27}$ There is evidence for intrathecal conversion of complement in Behçet's disease. ${ }^{44}$ About half of these patients have CSF polymorphs, which must also be giving some clue as to its underlying pathogenesis.

In sarcoid just over half have antibodies against the Kveim antigen which is used as a substrate for the immunoblotting after isoelectric focusing. ${ }^{45}$

Because patients with ataxia telangectasia

Table 2 Inflammatory disorders of the CNS associated with oligoclonal Ig G bands

\begin{tabular}{|c|c|c|}
\hline Disorder & $\begin{array}{l}\text { Approximate } \\
\text { incidence of } \\
\text { oligoclonal } \\
\text { bands }(\%)\end{array}$ & $\begin{array}{l}\text { Suggested } \\
\text { supplementary } \\
\text { investigations }\end{array}$ \\
\hline MS & 97 & MRI \\
\hline SSPE & 100 & Antimeasles antibody \\
\hline Neurosyphilis & 95 & $\begin{array}{l}\text { Antitreponemal } \\
\text { antibody }\end{array}$ \\
\hline Neuro-AIDS & 80 & Anti-HIV antibody \\
\hline Neuro-Lyme disease & 80 & Antiborrelia antibody \\
\hline Neuro-SLEE & 50 & Antinuclear factor \\
\hline Neuro-Behçet's & 20 & $\begin{array}{l}\mathrm{C}^{\prime} 3 \text { and } \mathrm{CSF} \\
\text { polymorphs }\end{array}$ \\
\hline Neuro-sarcoid & 40 & Kveim test \\
\hline Ataxia-telangecta & 60 & Serum IgA \\
\hline Adrenoleukodystrophy & 100 & Long chain fatty acids \\
\hline Harada's meningitis- & & \\
\hline $\begin{array}{l}\text { uveitis } \\
\text { Acute encephalitis }\end{array}$ & 60 & Serum CRP \\
\hline (< 7 days) & $<5$ & Viral antibody \\
\hline $\begin{array}{l}\text { Acute meningitis } \\
(<7 \text { days })\end{array}$ & $<5$ & $\begin{array}{l}\text { CSF lactate, serum } \\
\text { CRP }\end{array}$ \\
\hline Tumour & $<5$ & Brain scan \\
\hline
\end{tabular}

Table 3 Categories of patients in whom local synthesis of oligoclonal bands is not found

\begin{tabular}{l}
\hline Disease category \\
\hline Bands are not found when infectious disorders are excluded: \\
Congenital disorders \\
Vascular disorders \\
Headache and pain syndromes \\
Metabolic disorders \\
Paroxysmal disorders \\
Toxic disorders \\
Traumatic and sequelae \\
Skeletal and sequelae including myelopathy \\
Systematic disorders \\
Psychiatric disorders \\
Degenerative \\
Parkinson's disease \\
Autonomic failure \\
Alzheimer's disease and other dementias \\
Motor neuron disease \\
Spinal muscular atrophy \\
Hereditary degenerations \\
Idiopathic cerebellar, spinocerebellar degenerations \\
Bands are not found when complicating cases are excluded: \\
Neuropathies and myopathies \\
Peripheral neuropathies (hereditary and acquired) \\
Radicular syndromes \\
Isolated peripheral nerve lesions \\
Metabolic myopathies \\
Other groups in which local synthesis of bands is not found: \\
Isolated myelopathies \\
Guillain-Barre syndrome \\
Isolated intracranial hypertension \\
\hline
\end{tabular}

are known to have a low serum IgA, the oligoclonal response may be due to the exogenous immunoglobulins which are given to these patients to help prevent infections. Nevertheless, some still show local synthesis of bands which are not transferred from the serum. ${ }^{46}$

In adrenoleukodystrophy, in which there is no obvious aetiology for the oligoclonal response-the presence of abnormal long chain fatty acids may have a kind of "adjuvant" effect to allow the consequent production of intrathecal immunoglobulins. ${ }^{47}$

It may also be worth noting a list of diseases in which we have not found local synthesis of oligoclonal bands as previous techniques may have yielded differing results (table 3 ). ${ }^{22}$

The presence of oligoclonal bands in both serum and CSF, the so-called "mirror" pattern, has different connotations which will be considered under the next section concerning the differential diagnosis of two of the five types of banding patterns seen on isoelectric focusing.

DIFFERENTIAL DIAGNOSIS OF MIRROR PATTERN OLIGOCLONAL BANDS (SYSTEMIC SYNTHESIS)

The "mirror" pattern does not denote local synthesis of IgG within the CNS but rather the preponderance of the systemic oligoclonal response (see table 4).

The "mirror" pattern typically indicates a systemic type disease ${ }^{48}$ whereas the "greater than" pattern is typical of infections (and to a lesser degree autoimmune diseases) and of multiple sclerosis. Given the possibility of infection, one should also consider table 1 for specific antigens as well as the infective/ autoimmune diseases in table 2 . The likelihood of a "mirror" pattern is roughly evenly divided between: infection, autoimmune diseases, neoplastic (paraneoplastic to a lesser degree), Guillain-Barré syndrome, and other peripheral neuropathies, but occasionally vascular (autoimmune) or degenerative disease.

Either pattern basically reflects systemic synthesis of antibody which could bind to infectious antigens and we therefore require the additional technique of impregnating the nitrocellulose with the antigen in question so that only the stereospecific antibodies will bind. With the more general technique applied to the diagnosis of multiple sclerosis,

Table 4 Differential diagnosis for the "mirror" $(*)$ and "greater than" ( $(>)$ patterns of oligoclonal response with $\%$ given for each pattern (number of cases)

\begin{tabular}{|c|c|c|}
\hline * & Diagnosis & $>$ \\
\hline $\begin{array}{l}14(8) \\
18(10)\end{array}$ & $\begin{array}{l}\text { Infection } \\
\text { Autoimmune }\end{array}$ & $\begin{aligned} & 29(13) \\
& 9(4)\end{aligned}$ \\
\hline $\begin{aligned} 16(9) \\
5(3)\end{aligned}$ & $\begin{array}{l}\text { Neoplastic } \\
\text { Paraneoplastic }\end{array}$ & $\begin{array}{l}2(1) \\
1(2)\end{array}$ \\
\hline $\begin{array}{l}16(9) \\
18(10)\end{array}$ & $\begin{array}{l}\text { Guillain-Barré Syndrome } \\
\text { P. Neuropathy }\end{array}$ & $\begin{array}{l}0(0) \\
0(0)\end{array}$ \\
\hline $2(1)$ & MS & $57(26)$ \\
\hline $\begin{array}{c}5(3) \\
5(3) \\
(56)\end{array}$ & $\begin{array}{l}\text { Vascular } \\
\text { Degenerative } \\
\text { Total }\end{array}$ & $\begin{array}{l}0(0) \\
0(0) \\
\quad(46)\end{array}$ \\
\hline
\end{tabular}


the total IgG population is bound to nitrocellulose regardless of antigenic specificity. Some patients with multiple sclerosis have systemic bands which must be giving us some clue concerning the pathogenesis of this disease. Further work is thus indicated.

\section{Prognosis and "predicting" response to treatment}

Although some brain specific proteins (including the best studied case of myelin basic protein), have been found in CSF, blood, and urine, the main use of these proteins has been in sequential studies of their serum concentrations as an aid to prognosis in brain trauma. The higher the concentrations, as well as the longer their persistence at high concentrations, the worse the prognosis. ${ }^{49}$

Most predictive studies have been applied to the question of isolated syndromes such as optic neuritis-that is, will they progress to multiple sclerosis? Many investigators agree that the presence of oligoclonal bands makes it more likely that the patient will develop full blown multiple sclerosis, but the difference is not sufficiently great to be of help in giving advice to individual patients. ${ }^{50}$ Nevertheless, because of the statistically significant findings, it does reinforce the idea that oligoclonal bands play some part in the pathogenesis, although their precise role remains uncertain. The amount of IgG in the CSF correlates with the Kurtzke disability scale, but not with the duration of the disease. ${ }^{51}$ Patients with recent exacerbations have increased numbers of bands of free light chains, as determined by electrophoretic separation followed by immunofixation. ${ }^{52}{ }^{53}$ Conversely, in patients with a long duration (typically more than seven years), free light chains tend to disappear.

Clinical correlations can be found with raised CSF IgG and whether multiple sclerosis pursues a "benign" or "malignant" course, namely the Kurtzke score divided by the duration as defined by Poser. ${ }^{51} 54$

There is a separate aspect to prognosisnamely, its broad use in terms of prediction of response to treatment. Myelin basic protein constitutes a major marker for destruction and possible remyelination of white matter. ${ }^{55}$ Whitaker et al were able to show statistically significant differences in the positive response to steroids over five to 40 days when they separated patients into two groups using the cut off value of $0.1 \mathrm{ng} / \mathrm{ml}$ of CSF myelin basic protein, whereas there was no significant difference in the first five days. ${ }^{56}$ Thus patients with raised concentrations were more likely to show a response to steroids over two to five weeks than those with no increase in CSF myelin basic protein.

\section{Therapy and the search for surrogate markers}

Re-examination of CSF is helpful in monitoring the expected response to drug treatment in diseases such as tuberculous meningitis and syphilis.
The more fundamental question relates to what markers can be used (either molecular, functional, or anatomical) for response to therapy, namely the quest for surrogate markers which can supply additional information to clinical signs and symptoms. This is a slightly different question from trying to distinguish responders from non-respondersthat is, how great is the response of the surrogate marker, and does it parallel the clinical response? In comparing the clinical with the anatomical (MRI) and the molecular (immunology), these can be thought of as successively lower layers of the "iceberg" in which we normally only see the clinical "tip". Just as MRI shows additional (non-clinical) activity, so also the immunological studies show additional (non-MRI!) activity. ${ }^{19}$ Longitudinal studies of CSF light chain bands have shown that treatment of patients with multiple sclerosis with cyclosporin A showed a significant decrease in their production compared with placebo controls. ${ }^{57}$

Myelin basic protein is also being revisited because of the search for potential surrogate markers in response to $\beta$ interferon and other therapies. The studies of Whitaker et al on urinary myelin basic protein were less rewarding in predicting who might respond to $\beta$ interferon than the statistically significant difference which they found for CSF myelin basic protein in predicting response to steroids which was described in the previous section. ${ }^{58}$ Nevertheless, large amounts of urinary myelin basic protein were found in patients with the progressive form of multiple sclerosis. It is especially important to look for surrogate markers in the patients with the progressive form of the disease, as their MRIs do not usually show gadolinium enhancement, unlike the scans in the relapsing and remitting forms.

1 Streilein JW. Immunology, regional. In: Streilein JW, ed. Encyclopedia of human biology. New York: Academic Press 1991:391-400.

2 Cserr HF, Knopf PM. Cervical lymphatics, the blood-brain barrier and the immunoreactivity of the brain: a new view. Immunology Today 1992;13:507-12.

3 Felgenhauer K. Protein size and cerebrospinal fluid composition. Klinische Wochenschrift 1974;52:1158-64.

4 Norman PM. Cerebrospinal fluids. In: Coleman DV Chapman PA, eds. Clinical cytotechnology. London: Chapman PA, eds. Clinical

5 Schädlich HJ, Felgenhauer K. Diagnostic significance of IgG-synthesizing activated B cells in acute inflammatory diseases of the central nervous system. Klinisch Wochenschrift 1985;63:505-10

6 Thompson EJ, Norman P, MacDermot J. The analysis of cerebrospinal fluid. Br f Hosp Med 1975;14:645-52.

7 McLean BN. The detection of viral antigen in the cerebrospinal fluid of patients with herpes simplex virus encephalitis. [MD thesis], University of Edinburgh, 1990:1-267.

8 Boerman RH, Arnoldus EPJ, Bloem BR, Raap AK, Peters ACB. PCR in herpes simplex virus infections of the central nervous system. Serodiagnosis and Immunotherapy in Infectious Disease 1994;6:179-84.

9 Tyler KL. Polymerase chain reaction and the diagnosis of viral central nervous system diseases. Ann Neurol 1994; 36:809-11.

10 Noordhoek GT, Kolk AHJ, Bjune G, Catty D, Dale JW, Fine PEM, et al. Sensitivity and specificity of PCR for detection of Mycobacterium tuberculosis: a blind comparidetection of Mycobacterium tuberculosis: a blind comparison study among

11 Baringer JR, Pisani P. Herpes simplex virus genomes in human nervous system tissue analyzed by polymerase chain reaction. Ann Neurol 1994;36:823-9.

2 Kamei S, Tetsuka T, Takasu T, Shimizu K. New noninvasive rapid diagnosis of herpes-simplex virus encephalitis by quantitative detection of intrathecal antigen with a chemiluminescence assay. If Neurol Neurosurg Psychiatry 1994;57:1112-4. 
13 Wahlgren NG, Lindquist C. Haem derivatives in the cerebrospinal fluid after intracranial haemorrhage. Eur Neurol 1987;26:216-21.

14 Keir G, Tasdemir N, Thompson EJ. Cerebrospinal fluid ferritin in brain necrosis: evidence for local synthesis. Clin Chim Acta 1993;216:153-66.

15 Keir G, Zeman A, Brookes G, Porter M, Thompson EJ. Immunoblotting of transferrin in the identification of cerebrospinal fluid otorrhoea and rhinorrhoea. Ann Clin Biochem 1992;29:210-3.

16 McLean BM, Zeman A, Barnes D, Thompson EJ Patterns of blood brain barrier impairment and clinical features in multiple sclerosis. $f$ Neurol Neurosur Psychiatry 1993;56:356-60.

17 Hans P, Albert A, Franssen C, Born J. Improved outcome prediction based on CSF extrapolated creatine kinase $\mathrm{BB}$ isoenzyme activity and other risk factors in severe head injury. F Neurosurg 1989;71:54-8.

18 Sindic CJM. Collet-Cassart D, Depré A, Laterre EC Masson PL. C-reactive protein in serum and cerebrospinal fluid in various neurological disorders. $\mathcal{f}$ Neurol Sci 1984;63:339-44.

19 Dowling PC, Cook SD. Disease markers in acute multiple sclerosis. Arch Neurol 1976;33:668-70.

20 Fredrikson S, Link H, Eneroth P. CSF neopterin as marker of disease activity in multiple sclerosis. Acta Neurol Scand 1987;75:352-5.

21 Giovannoni G, Thorpe JW, Kidd D, Thompson AJ, Keir G, Miller DH, Thompson EJ. Soluble E-selectin in multiple sclerosis: clinical and MRI correlation. Neuroimmunol 1994;54:164.

22 McLean BN, Luxton RW, Thompson EJ. A study of immunoglobulin $G$ in the cerebrospinal fluid of 1007 patients with suspected neurological disease using isopatients with suspected neurological disease using iso113:1269-89.

23 Luxton RW, McLean BN, Thompson EJ. Isoelectric focusing versus quantitative measurements in the detection of intrathecal local synthesis of IgG. Clin Chim Act 1990;187:297-308.

24 Andersson A, Alvarez-Cermeño J, Bernardi G, Cogato I Fredman P, Fredriksen J, et al. The role of cerebrospinal fluid analysis in the diagnosis of multiple sclerosis: consensus report. $\mathcal{F}$ Neurol Neurosurg Psychiatry 1994: 7:897-903.

25 Felgenhauer K, Schädlich H-J, Nekic M, Ackermann R. Cerebrospinal fluid virus antibodies. A diagnostic indicator for multiple sclerosis? $\mathcal{F}$ Neurol Sci 1985;71: 291-9.

26 Reiber H, Lange P. Quantification of virus-specific antibodies in cerebrospinal fluid and serum: sensitive and specific detection of antibody synthesis in brain. Clin Chem 1991;37:1153-60.

27 Luxton RW, Zeman A, Holzel H, Harvey P, Wilson J, Kocen $\mathrm{R}$, et al. Affinity of antigen specific-IgG distin guishes multiple sclerosis from encephalitis. $\mathcal{f}$ Neurol $S c$ 1995 (in press)

28 Luxton RW, Thompson EJ. Affinity distribution of antigen-specific IgG in patients with multiple sclerosis and in patients with viral encephalitis. F Immunol Methods 1990;131:277-82.

29 Luxton RW, Thompson EJ. Differential oligoclonal band patterns on polyvinyldifluoride membranes. Immuno Methods 1989;121:269-74.

30 Lindquist L, Linné T, Hansson L-O, Kalin M, Axelsson $G$. Value of cerebrospinal fluid analysis in the differential diagnosis of meningitis: a study in 710 patients with susdiagnosis of meningitis: a study in 710 patients with suspected central nervous system in
Microbiol Infect Dis 1988;7:374-380.

31 Kleine TO, Baerlocher K, Niederer V, Keller H, Reutte F, Tritschler W, Bablok W. Diagnostiche Bedeutung der lactat bestimmung im liquor bei meningitis. Dtsch Med Wochenschr 1979;104:553-7.

32 Thompson EJ. Nervous System. In: Noe DA, Rock RC eds. Laboratory Medicine: New York: Williams and Wilkins, 1994:462-75.

33 Hughes GRV. The antiphospholipid syndrome: ten years on. Lancet 1993;342:341-4.

34 Jacobi C, Reiber J, Felgenhauer $\mathrm{K}$. The clinical relevance of locally produced carcinoembryonic antigen in of locally produced carcinoembryonic an

35 Thompson EJ. CSF Proteins: a biochemical approach. Amsterdam: Elsevier, 1988:117-20.

36 Jimi T, Wakayama Y, Shibuya S, Nakata H, Tomaru T, Takahashi $Y$, et al. High levels of nervous system-specific proteins in cerebrospinal fluid in patients with early stag Creutzfeldt-Jakob disease. Clin Chim Acta 1992;211: $37-46$
37 Schaarschmidt H, Prange HW, Reiber H. Neuronespecific enolase concentrations in blood as a prognostic parameter in cerebrovascular diseases. Stroke 1994,25: p58-65.

38 Moseley I. Imaging the adult brain. $f$ Neurol Neurosurg Psychiatry 1995;58:7-21.

39 Miller DH, Ormerod IEC, Rudge P, Kendall BE, Moseley IF, McDonald WI. The early risk of multiple sclerosis following isolated acute syndromes of the brainstem and spinal cord. Ann Neurol 1989;26:635-9.

40 Morrissey SP, Miller DH, Kendall BE, Kingsley DPE, Kelly MA, Francis DA, MacManus DG, McDonald WI. The significance of brain magnetic resonance imaging abnormalities at presentation with clinically isolated syndromes suggestive of multiple sclerosis. Brain 1993;116: $135-46$.

41 Reiber H. External quality assessment in clinical neurochemistry-survey of analysis for cerebrospinal fluid (CSF) proteins based on CSF serum quotients. Clin Chem 1995;41:256-63.

42 Paty DW, Oger JJF, Kastrukoff LF, Hashimoto SA, Hooge JP, Eisen AA, et al. MRI in the diagnosis of MS: a prospective study with comparison of clinical evaluation,
evoked potentials, oligoclonal banding, and CT. Neurology 1988;38:180-3

43 Filippini G, Comi GC, Cosi V, Bevilaqua L, Ferrarini M, Martinello V, et al. Sensitivities and predictive values of paraclinical tests for diagnosing multiple sclerosis. $\mathcal{F}$ Neurol 1994;241:132-7.

44 Aoyama J, Inaba G, Shimizu T. Third complement in cerebrospinal fluid in neuro-Behçets syndrome. 7 Neurol Sci 1979;41:183-90

45 McLean BN, Mitchell DN, Thompson EJ. Local synthesis of specific IgG in the cerebrospinal fluid of patients with neurosarcoidosis detected by antigen immunoblotting neurosarcoidosis detected by antigen immunoblot

46 Lowents Heule R. Oligoclonal gammopathy in ataxia-telangiectasia. Zeitschrift für Neurologie 1972;202:58-63.

47 Bernheimer H, Budka H, Müller P. Brain tissue Immunoglobulins in adrenoleukodystrophy: a comparison with multiple sclerosis and systemic lupus erythematosus. Neuropathol 1983;59:95-102.

48 Zeman A, McLean BN, Keir G, Luxton RW, Sharief MK, Thompson EJ. The significance of serum oligoclonal bands in neurological diseases. I Neurol Neurosurg Psychiatry 1993;56:32-5.

49 Thomas DGT, Palfreyman JW, Radcliffe DIG. Serum myelin basic protein assay in diagnosis and prognosis of patients with head injury. Lancet 1978;i:113-5.

50 Moulin D, Paty DW, Ebers GC. The predictive value of cerebrospinal fluid electrophoresis in "possible" multiple sclerosis. Brain 1983;106:809-16.

51 Walker RWH, Thompson EJ, McDonald WI. Cerebrospinal fluid in multiple sclerosis: relationships between immunoglobulins, leucocytes and clinical features. 7 Neurol 1985;232:250-9.

52 Vakaet A, Thompson EJ. Free light chains in the cerebrospinal fluid: an indicator of recent immunological stimulation. F Neurol Neurosurg Psychiatry 1985;48:995-8.

53 Lolli F, Siracusa G, Amato MP, Fratiglione L, Dal Pozzo G, Galli E, Amaducci L. Intrathecal synthesis of free immunoglobulin light chains and IgM in initial multiple sclerosis. Acta Neurol Scand 1991;83:239-43.

54 Stendahl-Brodin L, Link $\mathrm{H}$. Relation between benign course of multiple sclerosis and low-grade humoral course of multiple sclerosis and low-grade humoral immune response in cerebrospinal

55 Cohen SR, Brooks BR, Herndon RM, Jubelt B, McKhann GM. A diagnostic index of active demyelination: myelin basic protein in cerebrospinal fluid. Ann Neurol 1980; 8:25-31

56 Whitaker JN, Layton BA, Herman PK, Kachelhofer RD, Burgard S, Bartolucci AA. Correlation of myelin basic protein-like material in cerebrospinal fluid of multiple sclerosis patients with their response to glucocorticoid treatment. Ann Neurol 1993;33:10-7.

57 McLean BN, Rudge P, Thompson EJ. Cyclosporin A curtails the progression of free light chain synthesis in the CSF of patients with multiple sclerosis. $₹$ Neurol Neurosurg Psychiatry 1989;52:529-31.

58 Whitaker JN, Williams PH, Layton BA, McFarland HF, Stone LA, Smith ME, et al. Correlation of clinical features and findings on cranial magnetic resonance imaging with urinary myelin basic protein-like material in patients with multiple sclerosis. Ann Neurol 1994; 35:577-85. 